REVISTA CIENTÍFICA RURAL

ISSN: $1413-8263 \quad 2525-6912$
Revista Técnico-Científica

\title{
PRODUÇÃO DE MUDAS DE Hymenaea courbaril L. EM DIFERENTES SUBSTRATOS
}

\author{
1'Laísa Leocádio Silva, ${ }^{1}$ Quizzi Maria Cordova Becker, ${ }^{2} J o s i a n e ~ O t a l a k o s k i, ~{ }^{2}$ Geri Eduardo Meneghello \\ ${ }^{1}$ Ministério do Meio Ambiente do Estado do Mato Grosso do Sul; 2Programa de Pós Graduação em Ciência e Tecnologia de \\ Sementes, na Universidade Federal de Pelotas - campus Capão do Leão.
}

RESUMO: Pertencente a familia Fabaceae, o Jatobá é amplamente utilizado no território brasileiro, sendo destinado principalmente para a construção civil. O estudo de metodologias que promovam a produção de mudas em viveiro é fundamental para acelerar, bem como uniformizar o estabelecimento inicial das plântulas e o plantio direto no campo. O substrato é essencial na fase de produção de mudas e é um dos componentes responsáveis para a obtenção de plantas sadias e vigorosas. O presente trabalho teve por objetivo avaliar o melhor substrato para a produção de mudas de jatobá (Hymenaea courbaril L.) com utilização de baixo nível tecnológico. Foram testados seis substratos: S1: terra, S2: areia lavada, S3: substrato comercial, S4: terra e substrato comercial (proporção 1:1), S5: areia lavada e substrato comercial (proporção 1:1), S6: terra, areia lavada e substrato comercial (proporção 1:1: 1). Avaliou-se aos 20, 40, 60 e 80 dias após a semeadura a altura das plantas, número de folhas por planta, diâmetro de caule e determinação de matéria seca, sendo as duas últimas variáveis avaliadas somente na última época. $A$ análise de variância mostrou que não houve diferença entre os substratos avaliados. Sendo assim, é possível produzir mudas de jatobá ( $H$. courbaril L.) com todos os substratos testados, com a adoção de baixo nível tecnológico.

Palavras-chave: espécie florestal, reflorestamento, crescimento, jatobá.

\section{PRODUCTION OF SEEDLINGS OF Hymenaea courbaril L. IN DIFFERENT SUBSTRATES}

ABSTRACT: Belonging to the Fabaceae family, Jatobá is widely used in Brazilian territory, and is mainly used for civil construction. The study of methodologies that promote the production of seedlings in nursery is fundamental to accelerate, as well as to standardize the initial establishment of seedlings and no-till in the field. The substrate is essential in the seedlings production phase and is one of the responsible components for obtaining healthy and vigorous plants. The objective of this work was to evaluate the best substrate for the production of jatobá (Hymenaea courbaril L.) seedlings with low technological level. Six substrates were tested: S1: soil, S2: washed sand, S3: commercial substrate, S4: soil and commercial substrate (1: 1 ratio), S5: washed sand and commercial substrate (1: 1 ratio) washed sand and 
commercial substrate (ratio 1: 1: 1). Plant height, number of leaves per plant, stem diameter and dry matter determination were evaluated at 20,40,60 and 80 days after sowing. The last two variables were evaluated only in the last season. The analysis of variance showed that there was no difference between the evaluated substrates. Thus, it is possible to produce jatobá (H. courbaril L.) seedlings with all the substrates tested, with the adoption of low technological level.

Keywords: Forest species, reforestation, growth, jatobá.

\section{INTRODUÇÃO}

O jatobá (Hymenaea courbaril L.) pertence à família Fabaceae (SOUSA et al., 2012). Além do nome comum já citado, dependendo da região também é chamado de jatai, jitai, farinheira, jataiba, burandã, imbiuva, jatobá miúdo e jatobá da caatinga. Possui diversas sinonímias botânicas, sendo as mais comuns $H$. stilbocarpa, $H$. splendida e H. confertifollia (LORENZI, 2016).

O jatobá é uma árvore de grande porte, podendo atingir de 30 a 40 metros de altura, possui tronco reto, podendo atingir 2 metros de diâmetro e sua casca é grossa com até 3 centímetros (LORENZI, 2016). É encontrado em todo o continente americano, em margens de rios e áreas de mata (SILVA JÚNIOR, 2009). No Brasil, pode ser encontrado desde o estado do Piauí até o norte do Paraná, desenvolvendo-se em florestas semideciduais (MENDONÇA et al., 1998).

Segundo Lorenzi (2016), a madeira é pesada, com densidade de $0,96 \mathrm{~g} \mathrm{~cm}^{3}$, sendo possível ser utilizada na construção civil, como vigas, caibros, acabamentos internos, assoalho, além de ser utilizada em artigos de esportes, cabos de ferramentas, peças torneadas, esquadrias e móveis, caracterizando-a com isso em espécie de interesse econômico.

Espécies que apresentam grande importância silvicultural e econômica têm despertado a atenção de pesquisadores, que buscam demonstrar e facilitar a propagação da espécie (NASCIMENTO et al. 2011). O estudo de metodologias que promovam a produção de mudas em viveiro é fundamental para acelerar, bem como uniformizar o estabelecimento inicial das plântulas e o plantio direto no campo (MATHEUS et al., 2010).

A prática de cultivar plantas utilizando substratos objetiva a determinação do melhor padrão vital de cultivo no menor tempo, nesse sentido, a sua escolha ocorre em função da facilidade e da eficiência do uso e do tipo de semente, pois, é onde o 
sistema radicular contribuirá no crescimento da parte aérea até o transplante (BRAGA JUNIOR et al., 2010).

A identificação de substratos de baixo custo e que ao mesmo tempo se mostrem adequados para a produção de mudas, possibilita aos viveiristas possibilidade melhor planejamento de sua atividade, bem como aumento na possibilidade de produzir mudas sadias e vigorosas, viabilizando a sua atividade e ao mesmo tempo contribuindo para a preservação das espécies. Diante disto, o objetivo do presente trabalho foi avaliar o desenvolvimento de mudas de Hymenaea courbaril, produzidas em diferentes substratos.

\section{MATERIAL E MÉTODOS}

Local de pesquisa e coleta do material

O presente estudo foi conduzido entre os meses de dezembro de 2015 a março de 2016, na cidade de Rondonópolis - MT, em local protegido por uma tela sombrite com luminosidade de 50\%, com dimensões de 1,60 m de comprimento, $2 \mathrm{~m}$ de largura e $2 \mathrm{~m}$ de altura.

A coleta do material botânico foi realizada na segunda quinzena de setembro em árvores matrizes localizadas na zona rural de Rondonópolis-MT. Os frutos coletados já estavam maduros e caídos no chão. As sementes foram extraídas do fruto e beneficiadas manualmente, retirando-se as quebradas e furadas, sendo então, acondicionadas em recipientes plásticos previamente higienizados e secos, afim de não comprometer a conservação das sementes.

\section{Superação de dormência}

Foi realizado o processo de superação de dormência com escarificação mecânica (lixa d'água número 120) na região oposta ao hilo (FREITAS et al., 2013).

\section{Tratamentos e semeadura}

Foram testados os seguintes substratos: S1: terra (horizonte B de um Argissolo), S2: areia lavada, S3: substrato comercial Plantmax ${ }^{\circledR}$, S4: terra e substrato comercial Plantmax $^{\circledR}$ (proporção 1:1), S5: areia lavada e substrato comercial Plantmax ${ }^{\circledR}$ (proporção 1:1), S6: terra, areia lavada e substrato comercial Plantmax ${ }^{\circledR}$ 
(proporção 1:1:1). As sementes foram semeadas em sacos de polietileno $10 \times 15$ $\mathrm{cm}$, na profundidade de quatro $\mathrm{cm}$.

Durante a condução do experimento, as mudas foram deixadas sob telado, apenas com retenção parcial da luz, as demais condições ambientais não foram controladas. Foram realizadas irrigações diárias, utilizando-se regador manual, de forma a suprir a demanda hídrica, exceto quando ocorreram precipitações.

Esta atividade foi realizada sempre no mesmo horário, ao final da tarde visando padronizar o procedimento experimental. Não foram realizadas adubações e tampouco foi necessária a realização de controle de pragas e doenças. Havendo o surgimento de plantas competidoras (daninhas), oriundas do banco de semente do substrato, estas foram removidas manualmente.

\section{Avaliações}

Foram realizadas avaliações aos 20, 40, 60 e 80 dias após a semeadura. Em cada uma das épocas foram realizadas as seguintes avaliações:

Número de folhas: realizada a partir de contagem manual, sendo computadas as folhas completamente abertas. Foram avaliados todos os exemplares em cada unidade experimental, sendo computado para fins de análise o valor médio. Os resultados foram expressos em número médio de folhas por planta.

Altura de plantas: realizada com auxílio de uma régua graduada, avaliando-se o comprimento deste o colo, até o meristema apical. Da mesma forma que para número de folhas, foram avaliadas todos os exemplares em cada unidade experimental, sendo computado para fins de análise o valor médio. Os resultados foram expressos em centímetros por plantas.

Diâmetro do Caule: realizada com auxílio de um paquímetro, na região do colo (ponto de transição entre sistema radicular e parte aérea). Esta avaliação foi realizada somente na última avaliação. Resultados expressos pela média em centímetros por planta.

Matéria seca da parte aérea das plantas: realizada somente na avaliação final. A parte aérea das plantas foi acondicionada em sacos de papel, que foram mantidas em estufa com circulação de ar a $65^{\circ} \mathrm{C}$ e após 72 horas foram pesadas em balança com precisão de 0,01 gramas. 
Delineamento Experimental e Procedimento Estatístico

$O$ experimento foi conduzido em blocos casualizados (DBC) com quatro repetições, sendo cada repetição representada por 10 sacos para produção de mudas, totalizando 24 unidades experimentais.

Para a realização das análises estatísticas, as médias foram submetidas à análise de variância (ANOVA) e havendo significância para a variável em estudo, utilizou-se teste de separação de médias, do contrário a análise tornou-se conclusiva, sendo que para tanto utilizou-se o programa SISVAR (FERREIRA, 2014).

Objetivando maximizar a informação obtida no experimento realizou-se uma análise comparativa entre as diferentes épocas e entre os tratamentos avaliados. Não foi possível considerar um experimento fatorial, pois algumas avaliações por serem destrutivas foram realizadas somente na última época.

\section{RESULTADOS}

A análise de variância mostrou que não houve diferença estatística para os parâmetros avaliados nas mudas desenvolvidas nos diferentes substratos utilizados neste estudo.

$\mathrm{Na}$ Figura 1 é apresentado o número médio de folhas que as plantas apresentaram em cada uma das quatro avaliações e em cada tratamento. Não foram encontradas diferenças estatísticas entre os substratos utilizados, o que permite fazer uma inferência inicial que todos possuem potencial para serem utilizados na produção de mudas da espécie. Pode-se perceber, que 20 dias após a semeadura, o número de folhas por tratamento é bastante expressivo, onde a média encontra-se em 4 folhas por planta. 


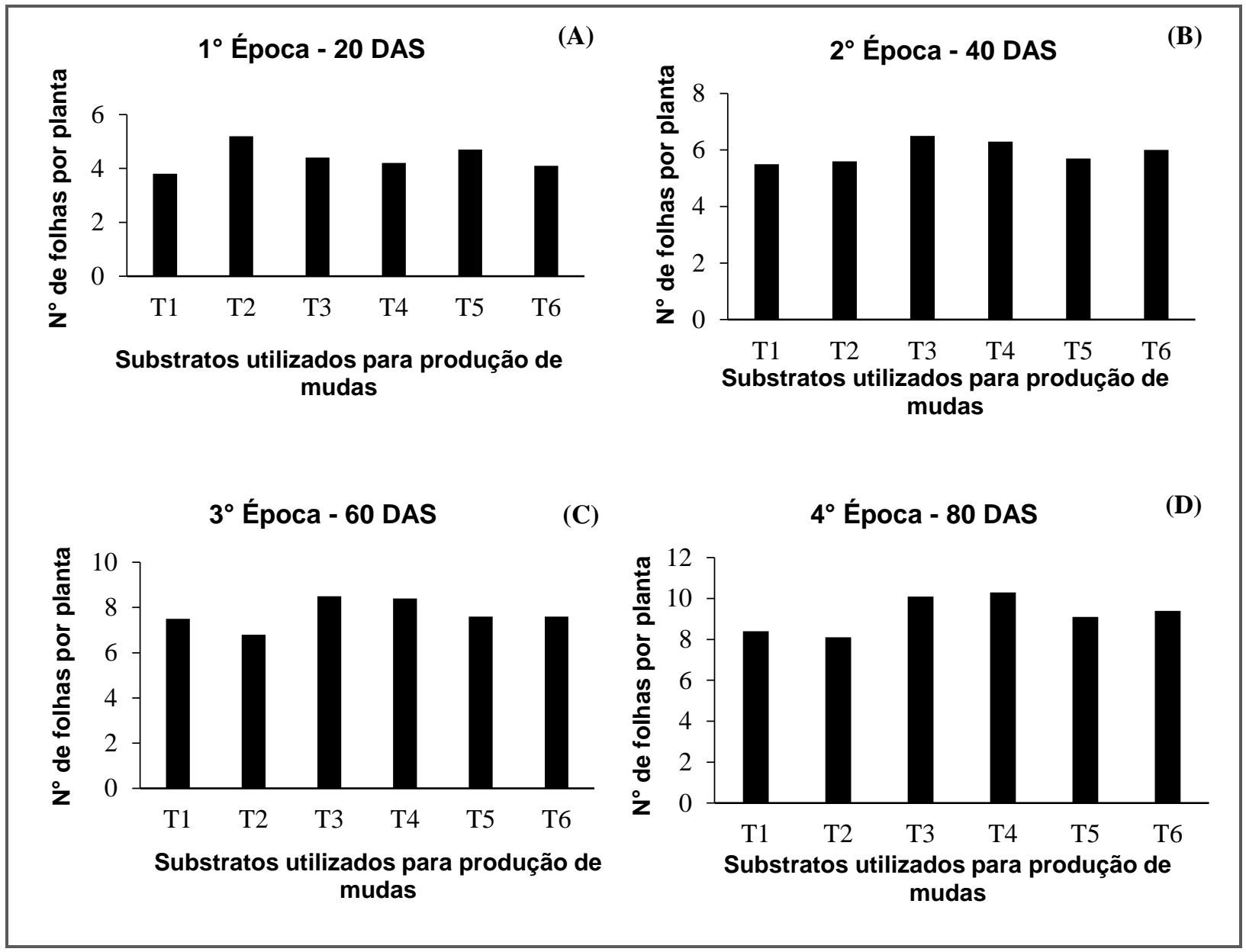

Figura 1. Número de folhas em mudas de Jatobá (H. courbaril), aos 20(A), 40 (B), 60 (C) e 80 (D) dias após a semeadura, produzidas em distintos substratos: T1: terra, T2: areia lavada, T3: substrato comercial, T4: terra e substrato comercial (proporção 1:1), T5: areia lavada e substrato comercial (proporção 1:1), T6: terra, areia lavada e substrato comercial (proporção 1:1:1).

Figure 1. Number of leaves plants of Jatobá (H. courbaril), at $20(A), 40(B), 60(C)$ and 80 (D) days after sowing, produced on different substrates: T1: soil, T2: sand T5: washed sand and commercial substrate (ratio 1: 1), T6: soil, washed sand and commercial substrate (ratio 1:1:1).

$\mathrm{Na}$ segunda avaliação que corresponde aos 40 dias o número de folhas sofreu pouca alteração, passando para cerca de cinco em cada muda (Figura 1B).

Da segunda para a terceira avaliação (Figura 1C) houve variação considerável para sete a oito folhas, verificando-se novamente uma tendência de redução na intensidade de surgimento de novas folhas na quarta época (Figura 1D), quando verificou-se 8 folhas.

Para o parâmetro altura de plantas, as mudasaos 20 dias após a semeadura, apresentavam-se com mais de $15 \mathrm{~cm}$ de altura (Figura 2A), alcançando aproximadamente $25 \mathrm{~cm}$ aos 40 dias (Figura 2B), $30 \mathrm{~cm}$ aos 60 dias (Figura 2C), 
com pequeno acréscimo entre esta época e a posterior, aos 80 dias (Figura 2D). Neste momento identificou-se uma maior variação entre os tratamentos embora não houvesse diferenças estatísticas entre eles.

Este pequeno crescimento verificado entre o período de 60 e 80 dias após a semeadura, pode estar associado à características genéticas da espécie.

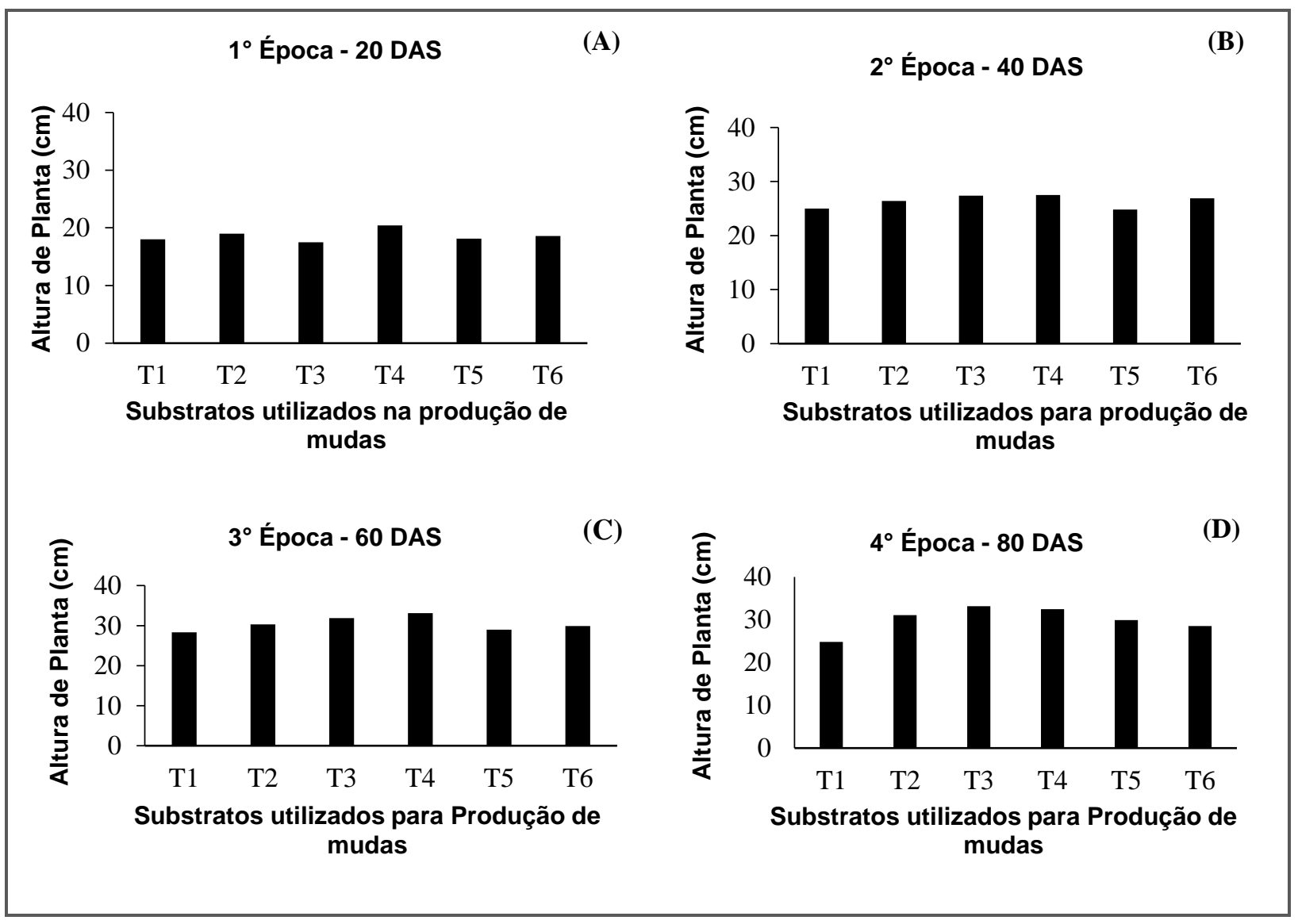

Figura 2. Altura de planta de Jatobá (H. courbaril), aos 20(A), 40 (B), 60 (C) e 80 (D) dias após a semeadura, produzidas em distintos substratos: T1: terra, T2: areia lavada, T3: substrato comercial, T4: terra e substrato comercial (proporção 1:1), T5: areia lavada e substrato comercial (proporção 1:1), T6: terra, areia lavada e substrato comercial (proporção 1:1:1).

Figure 2. Height of Jatobá plant Jatobá (H. courbaril), at 20 (A), 40 (B), 60 (C) and 80 (D) days after sowing, produced on different substrates: T1: soil, T2: sand T5: washed sand and commercial substrate (ratio 1: 1), T6: soil, washed sand and commercial substrate (ratio 1: 1:1).

A evolução do crescimento em altura das plantas, em cada um dos substratos utilizados pode ser observado na Figura 3. Chama atenção o maior crescimento observado na primeira época, seguido de incrementos com intensidade diferenciada entre os substratos, porém em todos, conforme mencionado, merece ser registrado o menor crescimento entre as duas últimas épocas avaliadas. 
No que tange ao diâmetro do caule aos 80 dias após a semeadura não foram observadas diferenças entre os substratos utilizados (Figura 4). Aliando os valores desta variável, em torno de $2,5 \mathrm{~cm}$, com a altura da planta, por volta de $30 \mathrm{~cm}$, é possível inferir que as mesmas estavam em condições adequadas para serem transplantadas, evidenciando que os substratos testados são adequados para a produção de mudas de jatobá, mesmo sendo empregado um baixo nível tecnológico, apenas com controle parcial de luminosidade (retenção de $50 \%$ da luz) e realização de irrigações diárias.

A exemplo das demais variáveis avaliadas neste estudo, não foi possível identificar diferenças significativas entre a matéria seca de plantas aos 80 dias após a semeadura (Figura 5). 


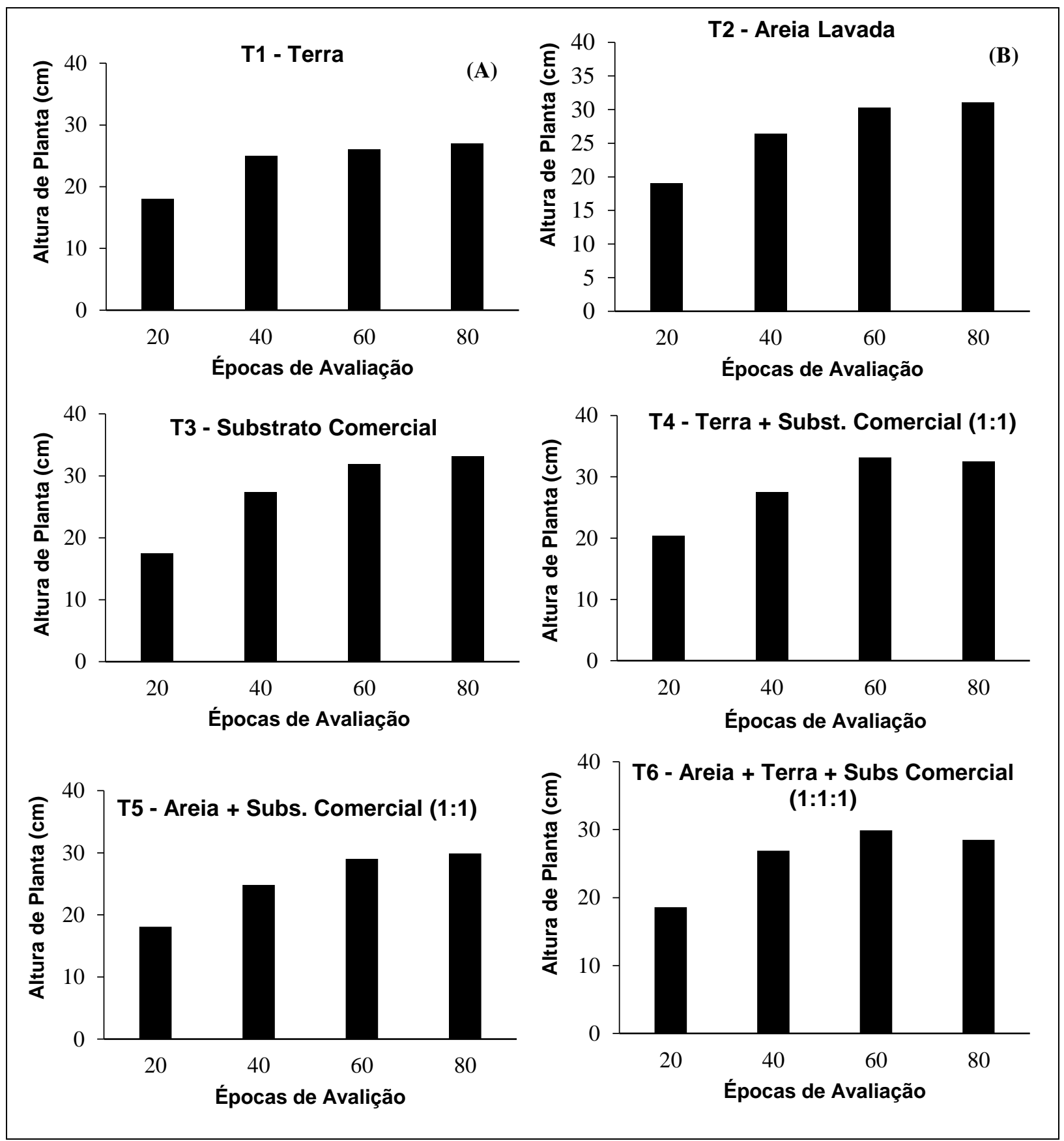

Figura 3. Evolução da altura de plantas de Jatobá (H. courbaril) ao longo dos períodos avaliados, produzidas em distintos substratos: T1: terra (A), T2: areia lavada (B), T3: substrato comercial (C), T4: terra e substrato comercial (proporção 1:1) (D), T5: areia lavada e substrato comercial (proporção 1:1) (E), T6: terra, areia lavada e substrato comercial (proporção 1:1:1).

Figure 3. Evolution of the height of Jatobá (H. courbaril) plants over the evaluated periods, produced on different substrates: T1: soil, T2: sand T5: washed sand and commercial substrate (ratio 1: 1), T6: soil, washed sand and commercial substrate (ratio $1: 1: 1$ ). 


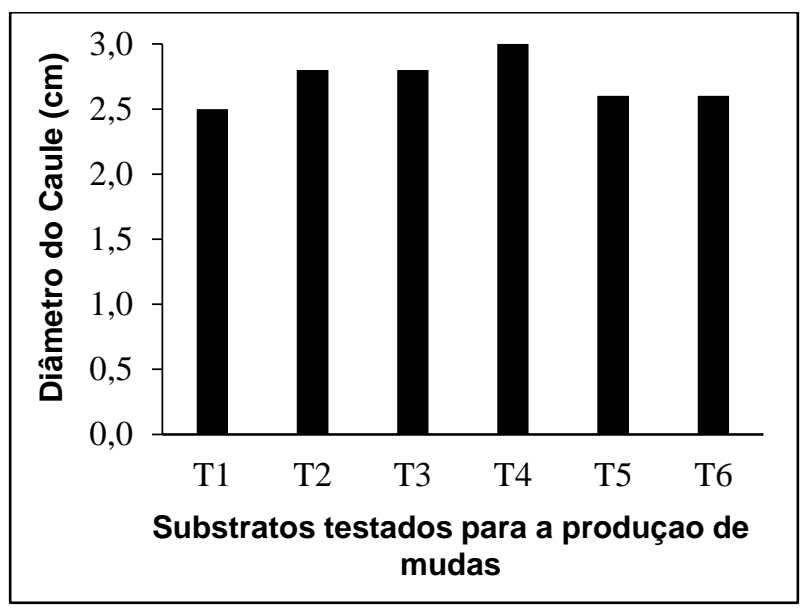

Figura 4. Diâmetro do caule de mudas Jatobá (H. courbaril), aos 80 dias após a semeadura, produzidas em distintos substratos: T1: terra, T2: areia lavada, T3: substrato comercial, T4: terra e substrato comercial (proporção 1:1), T5: areia lavada e substrato comercial (proporção 1:1), T6: terra, areia lavada e substrato comercial (proporção 1:1:1).

Figure 4. Diameter of stem of Jatobá plants (H. courbaril) produced on different substrates: T1: soil, T2: sand T5: washed sand and commercial substrate (ratio 1: 1), T6: soil, washed sand and commercial substrate (ratio 1:1:

1).

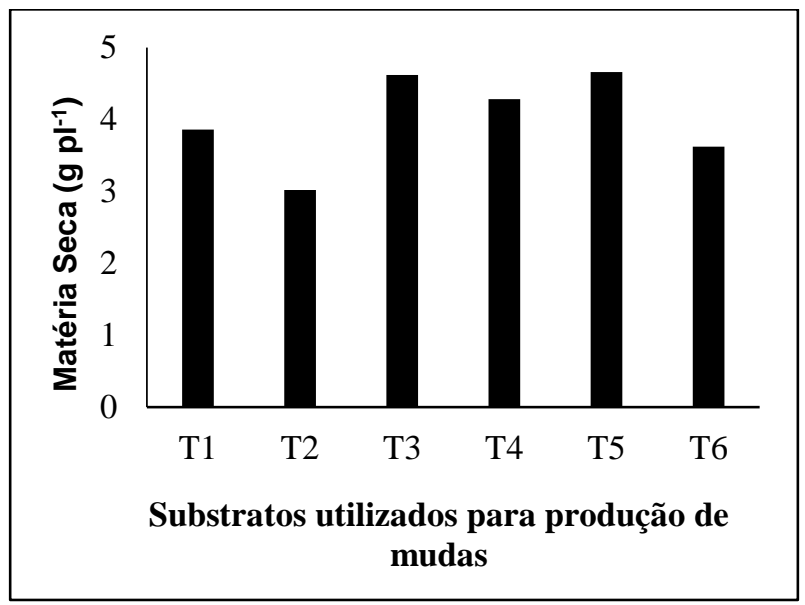

Figura 5. Matéria seca de mudas de Jatobá (H. courbaril), aos 80 dias após a semeadura, produzidas em distintos substratos: T1: terra, T2: areia lavada, T3: substrato comercial, T4: terra e substrato comercial (proporção 1:1), T5: areia lavada e substrato comercial (proporção 1:1), T6: terra, areia lavada e substrato comercial (proporção 1:1:1).

Figure 5. Dry matter of Jatobá ( $\mathrm{H}$. courbaril) seedlings at 80 days after sowing, produced in different substrates: T1: soil, T2: washed sand, T3: commercial substrate, T4: soil and commercial substrate (1: 1 ratio) , T5: washed sand and commercial substrate (ratio 1: 1), T6: soil, washed sand and commercial substrate (ratio 1:1:1). 


\section{DISCUSSÃO}

Costa Campos et al. (2008) afirmaram que para uma planta possa obter um bom crescimento e desenvolvimento, é necessário que em sua fase inicial haja uma maior quantidade de folhas para que ocorra uma intensa atividade fotossintética. $O$ número de folhas também atua como um bioindicador, pois age diretamente sobre o acúmulo de biomassa (CÂMARA; ENDRES, 2008).

Em relação a diâmetro do colo, Gomes e Paiva (2011) consideram a técnica como uma das mais importantes, pois, é fácil estimar a sobrevivência da planta após o plantio, também, por ser um método não destrutivo. Apesar de não ser considerado um índice de avaliação da qualidade de mudas, Gomes e Paiva (2011) afirmam que essa informação é capaz de predizer o potencial de sobrevivência da muda no campo, pois quanto mais lignificado seu caule se encontra maior é seu sucesso no campo.

Ferraz e Engel (2011) trabalhando com a produção de mudas de jatobá em diferentes recipientes, puderam verificar que mudas produzidas em tubetes de 300 $\mathrm{cm}^{3}$ atingem uma altura média de 33,5 cm em 130 dias após a emergência. Dados semelhantes aos constatados neste trabalho, onde é possível verificar na Figura 3, que aos 80 DAS à altura das plantas variou de 27 a $33 \mathrm{~cm}$.

Paiva et al. (2010) trabalhando com três espécies florestais do cerrado, verificaram que o uso de solo como substrato para produção de mudas proporcionou uma maior produção de massa fresca e seca de parte aérea e radicular.O peso de matéria seca é um dos parâmetros utilizados para verificar a estabilidade da planta a campo, pois, se estas apresentam parte aérea proeminente e sistema radicular pouco desenvolvido, podendo acarretar para o não estabelecimento da muda a campo, gerando tombamento (FERRAZ; ENGEL, 2011).

Com relação ao número de folhas, este comportamento demonstra que, a espécie, não apresenta um crescimento linear (constante), possivelmente esta seja uma estratégia adaptativa no processo de evolução das espécies, ou de adaptação as condições ambientais que podem ser distintas entre um período e outro.

Ao analisar a figura 4, é possível inferir que as mesmas estavam em condições adequadas para serem transplantadas, evidenciando que os substratos testados são adequados para a produção de mudas de jatobá, mesmo sendo empregado um 
baixo nível tecnológico, apenas com controle parcial de luminosidade (retenção de $50 \%$ da luz) e realização de irrigações diárias.

\section{CONCLUSÕES}

Todos os substratos testados (terra; areia lavada; substrato comercial; terra e substrato comercial; areia lavada e substrato comercial; terra, areia lavada e substrato comercial) podem ser utilizados para a produção de mudas de Jatobá, com adoção de baixo nível tecnológico.

\section{AGRADECIMENTOS}

O presente trabalho foi realizado com apoio da Coordenação de Aperfeiçoamento de Pessoal de Nível Superior - Brasil (CAPES).

\section{REFERÊNCIAS}

BRAGA JUNIOR, J.M.; BRUNO, R.L.A.; ALVES, E.U. Emergência de plântulas de Zizyphus joazeiro Mart. (Rhamnaceae) em função de substratos. Revista Árvore, Viçosa. v.34, n.4, p.609-616, 2010. DOI: 10.1590/S0100-67622010000400005.

CÂMARA, C. A.; ENDRES, L. Desenvolvimento de mudas de duas espécies arbóreas: Mimosa caesalpiniifolia Benth. e Sterculia foetida L. sob diferentes níveis de sombreamento em viveiro. Floresta, v. 38, n. 1, p. 43-51, 2008. DOI: http://dx.doi.org/10.5380/rf.v38i1.11026.

COSTA CAMPOS, M. C.; MARQUES, F. J.; GOMES DE LIMA, A.; NUNES DE MENDONÇA, R. M. Crescimento de porta-enxerto de gravioleira (Annona muricata L.) em substratos contendo doses crescentes de rejeitos de caulim. Revista de Biologia e Ciência da Terra, v. 8, n. 1, p. 61-66, 2008. Disponível em: http://www.redalyc.org/articulo.oa?id=50080106.

FERREIRA, Daniel Furtado. Sisvar: a Guide for its Bootstrap procedures in multiple comparisons. Ciênc. agrotec, vol.38, n.2, 2014.

FERRAZ, A. V. ENGEL, V. L. Efeito do tamanho de tubetes na qualidade de mudas de jatobá (Hymenaea courbaril I. Var. stilbocarpa (Hayne) lee et lang.), ipê-amarelo (Tabebuia chrysotricha (mart. ex dc.) sandl.) e guarucaia (Parapiptadenia rigida (benth.) brenan). Revista Árvore, v.35, n.3, p.413-423, 2011. DOI: http://dx.doi.org/10.1590/S0100-67622011000300005.

FREITAS, A. R.; LOPES, J.MC.; MATHEUS, M. T.; MENGARDA, L. H. G.; VENANCIO, L. P.; CALDEIRA, M. V. W. Superação da dormência de sementes de jatobá. Pesquisa Florestal Brasileira, Colombo, v. 33, n. 73, p. 85-89, 2013. DOI: https://doi.org/10.4336/2013.pfb.33.73.350. 
GOMES, J. M.; PAIVA, H. N. de. Viveiros Florestais: propagação sexuada. Viçosa: UFV, 2011. $116 \mathrm{p}$.

LORENZI, H. Árvores brasileiras: manual de identificação e cultivo de plantas arbóreas nativas do Brasil. 7.ed. Instituto Plantarum, Nova Odessa, v.1, p. 384, 2016.

MATHEUS, M.T.; GUIMARÃES, R.M.; BACELAR, M.; OLIVEIRA, S.A.S. Superação de dormência em sementes de duas espécies de Erythrina. Revista Caatinga, Mossoró, v. 23, n. 3, p.48-53, 2010. Disponível em: Disponível em: http://www.redalyc.org/articulo.oa?id=237116334008.

MENDONÇA, R.; FELFILI, J.M.; WALTER, B.M.T.; SILVA JÚNIOR, M.C.; REZENDE, A.V.; FILGUEIRAS, T.S.; NOGUEIRA, P.E.N. Flora vascular do Cerrado.. In: SANO, S.M.; ALMEIDA S.P. Cerrado: ambiente e flora. Planaltina: Embrapa-CPAC, p. 287-556, 1998.

NASCIMENTO, H. H. C.;MANSUR, R., CIRÍACO, E. Y ALMEIDA, M. Análise do crescimento de mudas de jatobá (Hymenaea courbaril L.) em diferentes níveis de água no solo. Revista Árvore. v.35, n.3, p. 617-626, 2011. DOI: http://dx.doi.org/10.1590/S010067622011000400005.

PAIVA, S.; LUZ, P.; SILVEIRA, T.; RAMOS, D.; NEVES, L.; BARELLI, M. Substratos na produção de mudas de três espécies arbóreas do cerrado. Revista Brasileira de Ciências Agrárias, v. 5, n. 2, p. 238-243, 2010. DOI: 10.5039/agraria.v5i2a741.

SILVA JÚNIOR, M.C. 100 Árvores do Cerrado: guia de campo. Rede de Sementes do Cerrado, Brasília, p. 288, 2009.

SOUSA, E.P.; SILVA, L.M.M.; SOUSA, F.C.; FERRAZ, R.R.; FAÇANHA, L.M. Caracterização Físico-Química da Polpa Farinácea e Semente do Jatobá. Revista Verde, Campina Grande. v.7, n. 2, p. 117-121, 2012. 